\title{
Iris Matching Using SURF Algorithm
}

\author{
Rana Saad Mohammed ${ }^{1}$, Nada Jasim Habeeb ${ }^{2}$ and Ziad Mohammed Abood ${ }^{3}$ \\ ${ }^{1}$ Computer Science Department, Education Collage, Al-Mustansiriyah University, \\ Baghdad, Iraq \\ ${ }^{2}$ Technical College of Management Collage, Middle Technical University, \\ Baghdad, Iraq \\ ${ }^{3}$ Physics Department, Education Collage, Al-Mustansiriyah University, \\ Baghdad, Iraq \\ ${ }^{1}$ Ranasaad2014@gmail.com, ${ }^{2}$ nadaj2013@gmail.com,

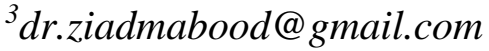

\begin{abstract}
Iris recognition is one of biometric techniques that provide fast and accurate for human identification. This paper studies four main types of iris (Jewel, flower, stream, and shaker). And also it studies a fast method using Speed Up Robust Features algorithm (SURF) for finding a match between original eye image and input eye image to the system with taking into account the speed of algorithm implementation and its compatibility with an iris scanner.
\end{abstract}

Keywords: Iris types, image, Biometrics, correlation, extract of features

\section{Introduction}

Biometric is a measurement that used to describe each individual characteristic from the other. The term "Biometric" is derived from Greek words "bio" meaning life and "metric" meaning to a measure [1]. There are two of traditional biometric systems: Token based identification systems (e.g., passport or driver's license) and knowledge based identification systems (e.g., password or personal identification number) [2].

In recent, biometric techniques depend on unique individual characteristics. There are two main types of biometric identifiers. A first type is physiological characteristic that relate to the shape or composition of the body for example fingerprint, DNA, face, hand, iris, retina or ear features. A second type is behavioral characteristic that relate to the behavior of a person for example typing rhythm, gait, gestures and voice [3]. Figure (1), describes these two types.

This paper focuses on four main types of iris: Jewel, flower, stream, and shaker. The trait of iris jewel type is brown freckle-like dots or flecks. The trait of iris flower type is curved or rounded openings, like flower petals. The trait of iris stream type is straight lines or streaks of color. The trait of iris shaker type is both dot-like/freckle-like pigments and rounded openings. Figure (2), shows these four main types of iris. 


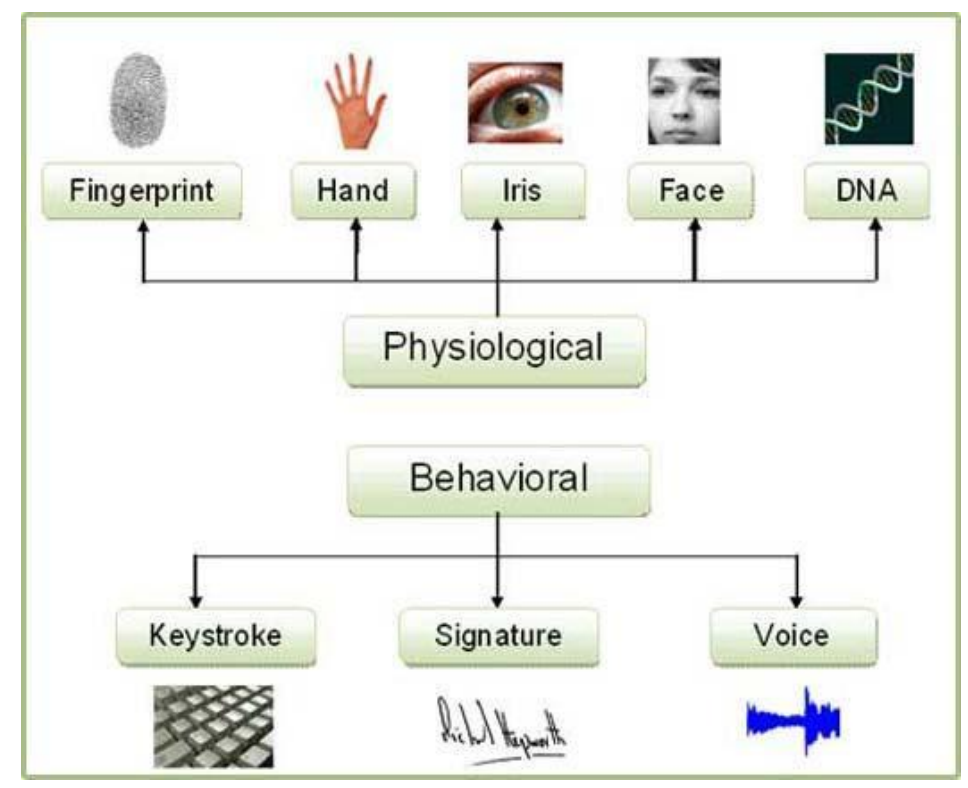

Figure 1. Two Main Types of Biometric Identifiers

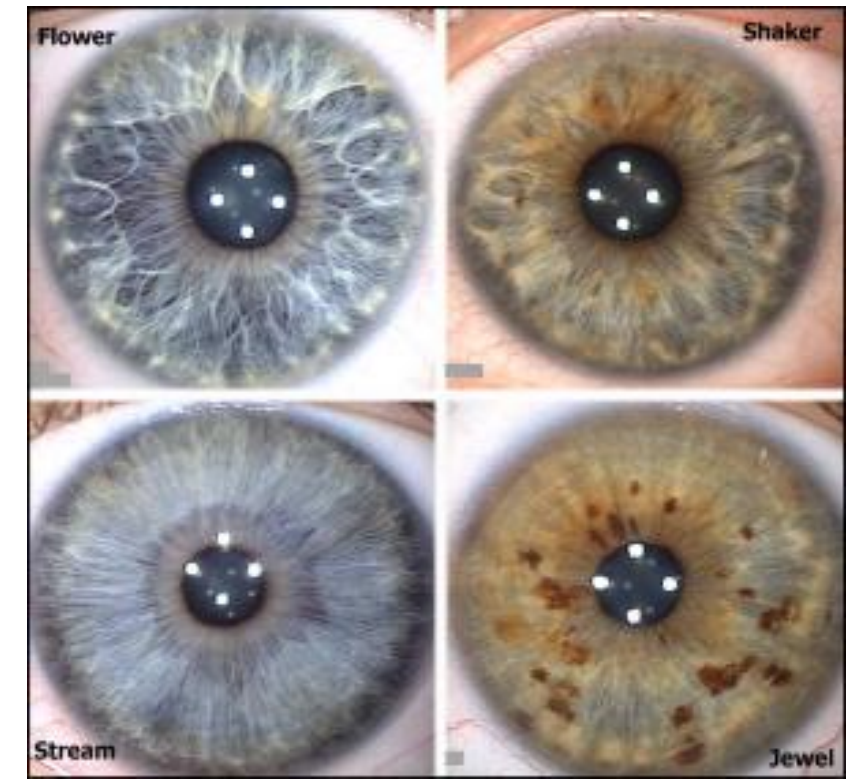

Figure 2. Four Main Types of Iris

The organization of this paper as follows: Matching with correlation in section II. The system overview in section III. The Experiment results in section IV. The conclusion in the last section.

\section{Matching with Correlation}

Matching is important step in iris recognition system that evaluates the similarity between original eye image and the input eye image to the system [4]. There are researches used Hamming distances for matching [5-8]. The other research used Normalized correlation for matching [9].In [10-11] used Euclidean distance for matching. In [12-14] used Band-limited phase only correlation for matching. The recent researches are: in [15] used Harris algorithm for matching. In [16] used Scale Invariant Feature Transform (SIFT) for matching. In [17] used SURF for matching.

This paper study used SURF for matching of four main types of iris (Jewel, flower, 
stream, and shaker).

\section{System Overview}

Figure (3), shows an overview of study system. At first read an iris photo and convert it into gray image. And then select a specific region to extract features. This study uses all region of iris to extract 100 strongest features using SURF algorithm to get a unique matching degree.

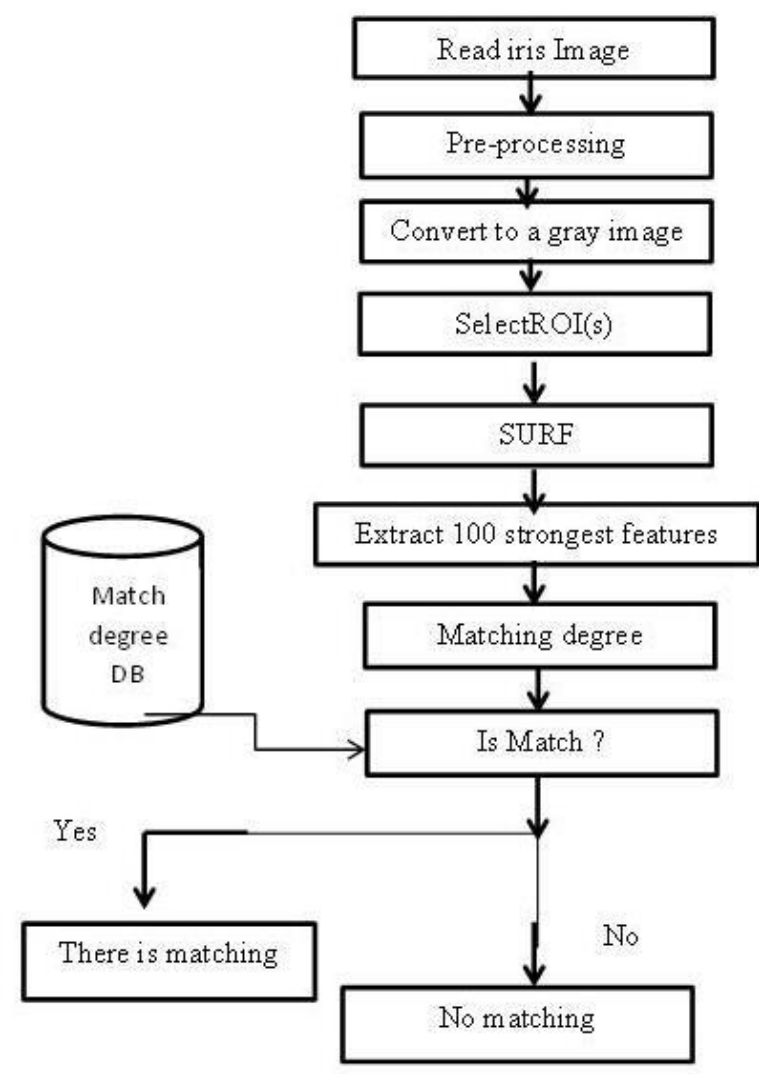

Figure 3. Overview of Study System

\section{Experimental Results}

Figure (4), shows study samples of four main types of iris (Jewel, flower, stream, and shaker). Figures (5-8), show study matching of these samples between each other. Tables (1-4), show the results of matching degree in this study. The results show the study method has fast, efficient and adequate with iris scanner devices to find a unique strongest features and matching degree. 

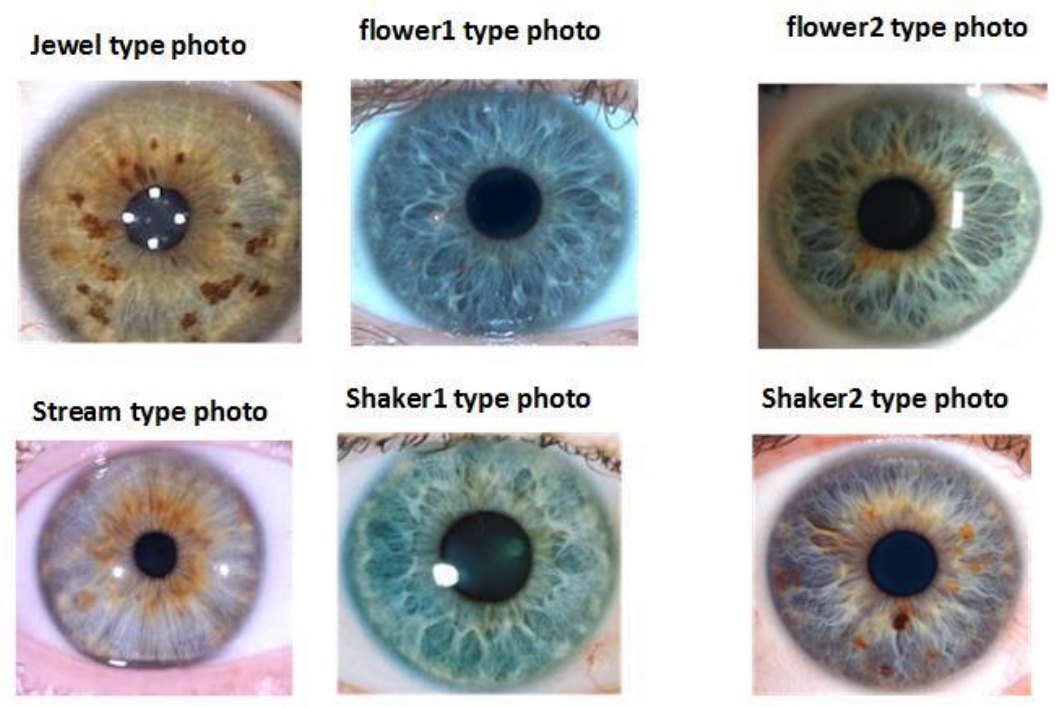

Shaker2 type photo

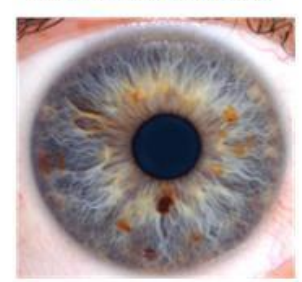

Figure 4. Study Samples
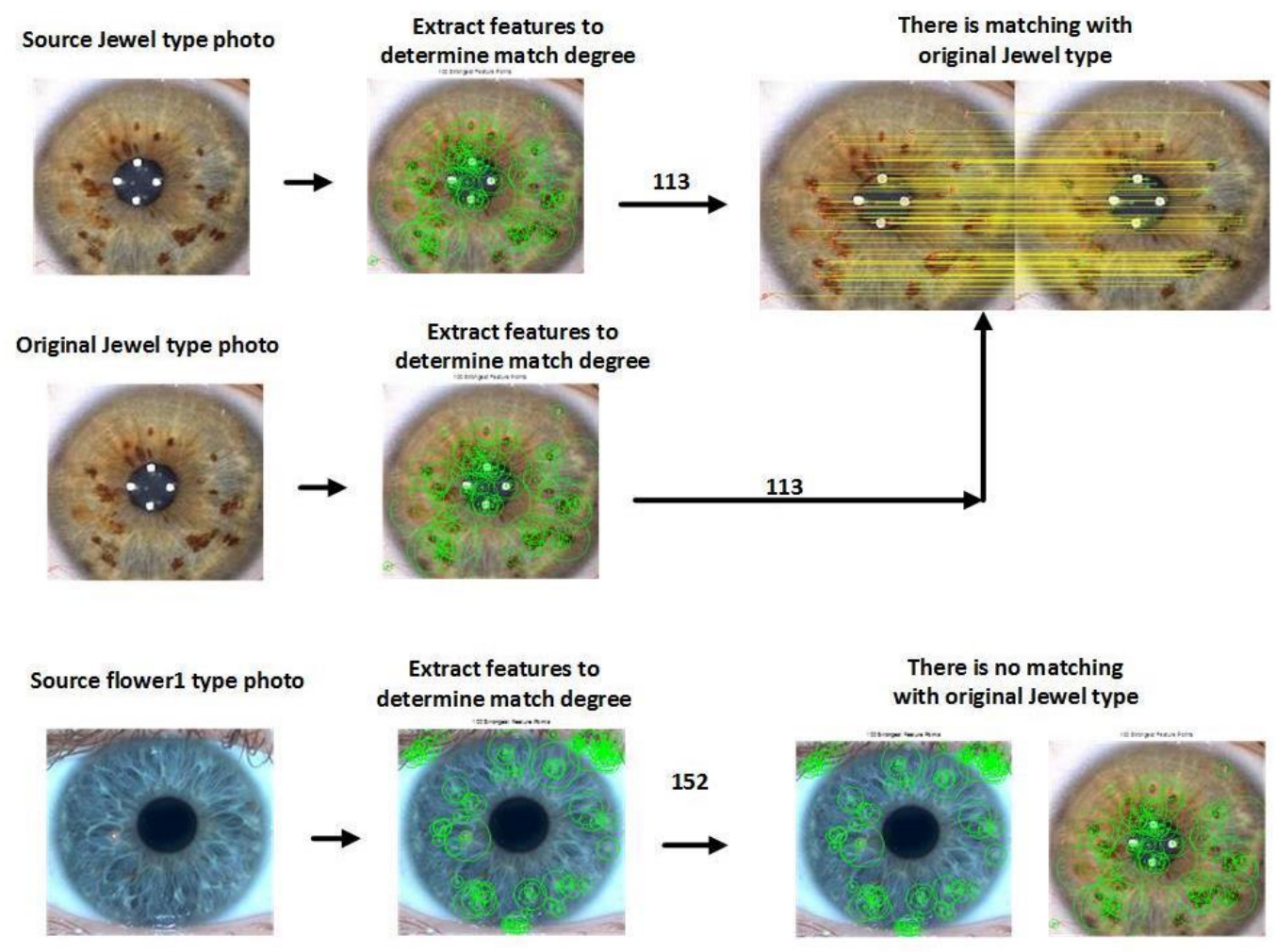

Figure 5. Study Matching of Samples with Jewel Iris Type (Continued) 


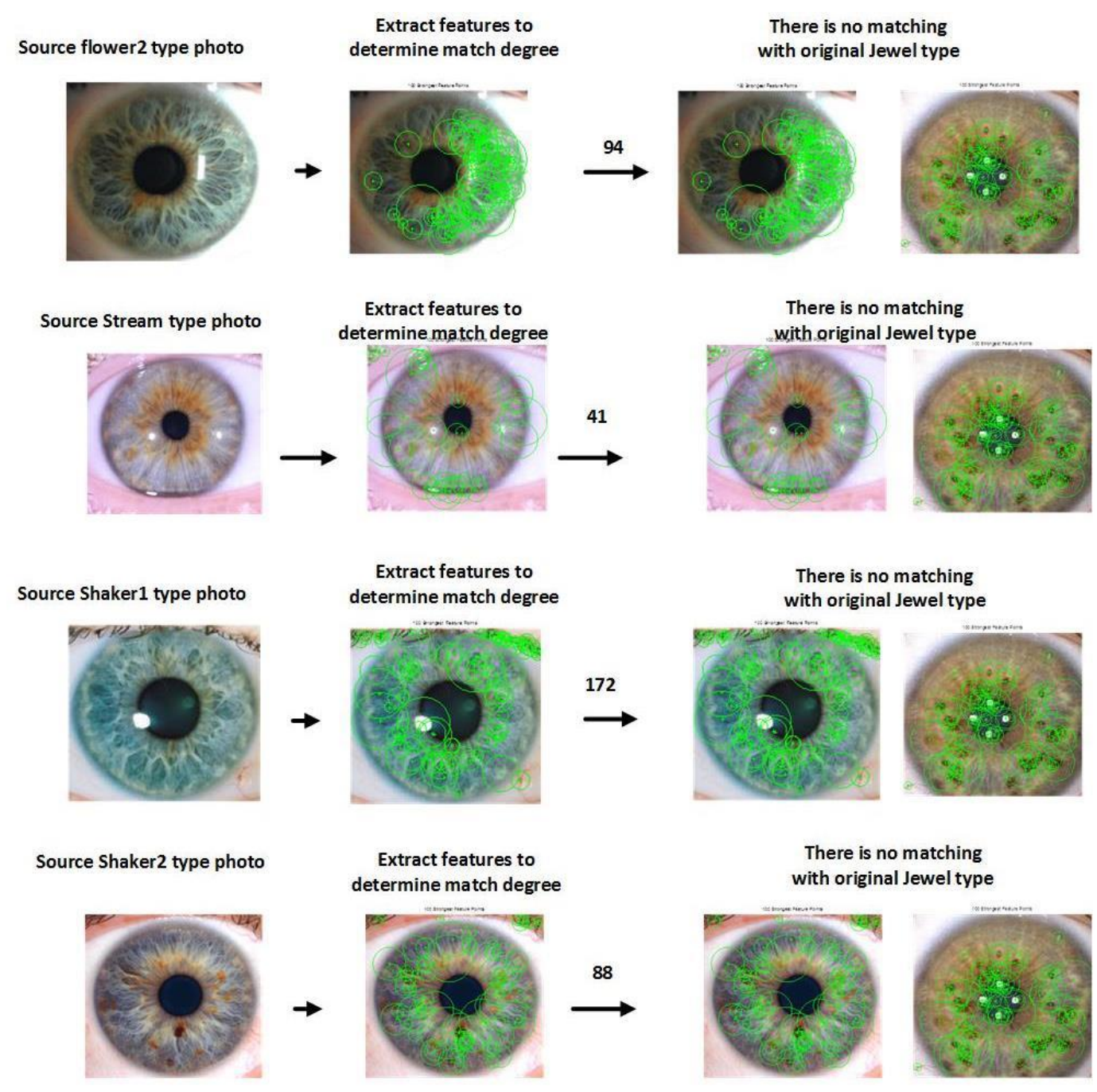

Supplement of Figure 5. Study Matching of Samples with Jewel Iris Type 


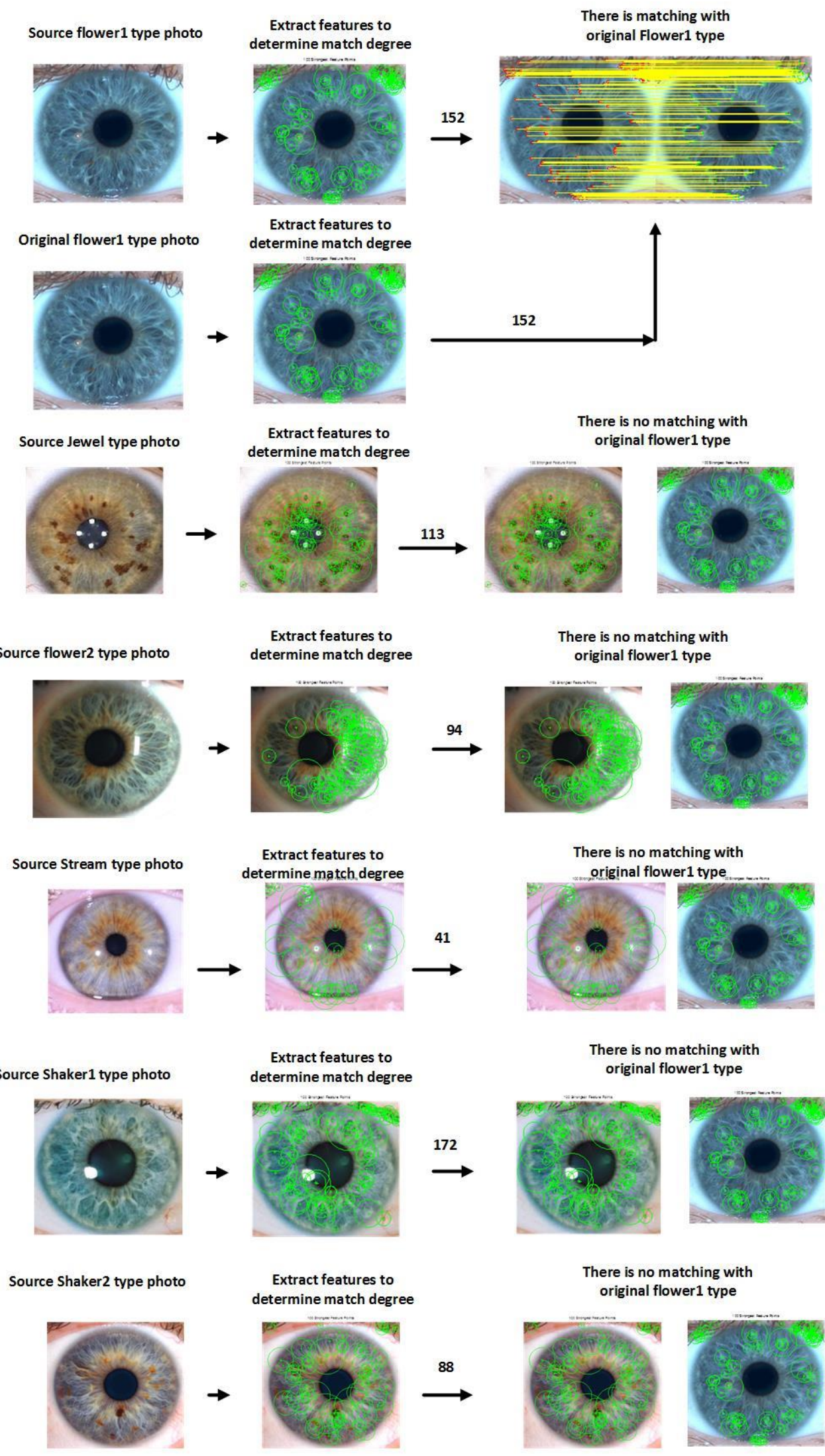

Figure 6. Study Matching of Samples with Flower 1 Iris Type 

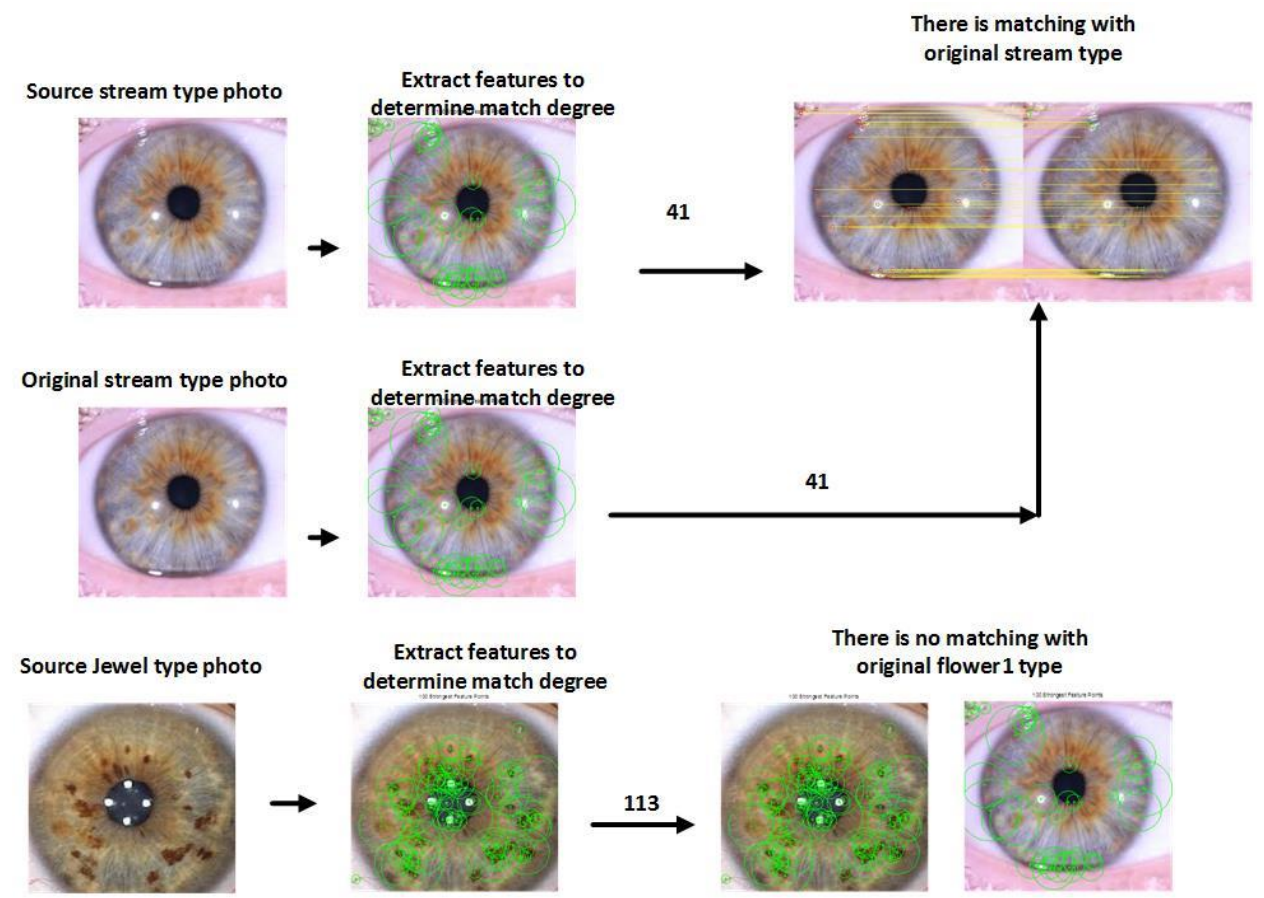

Source flower1 type photo
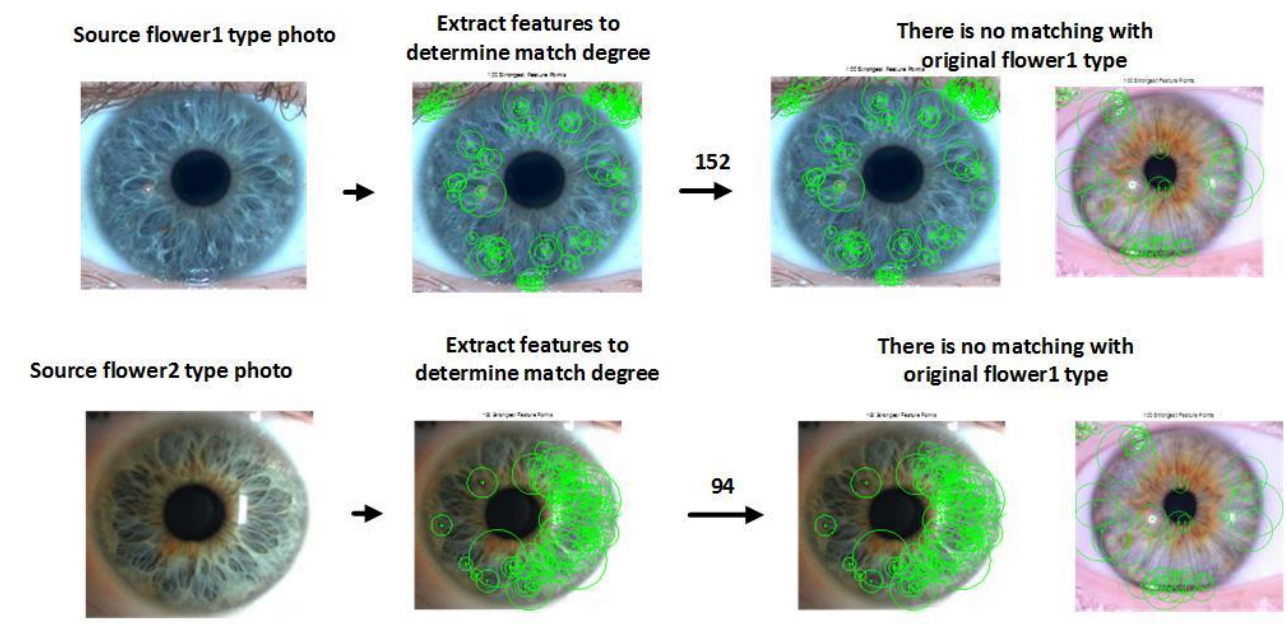

Extract features to determine match degree
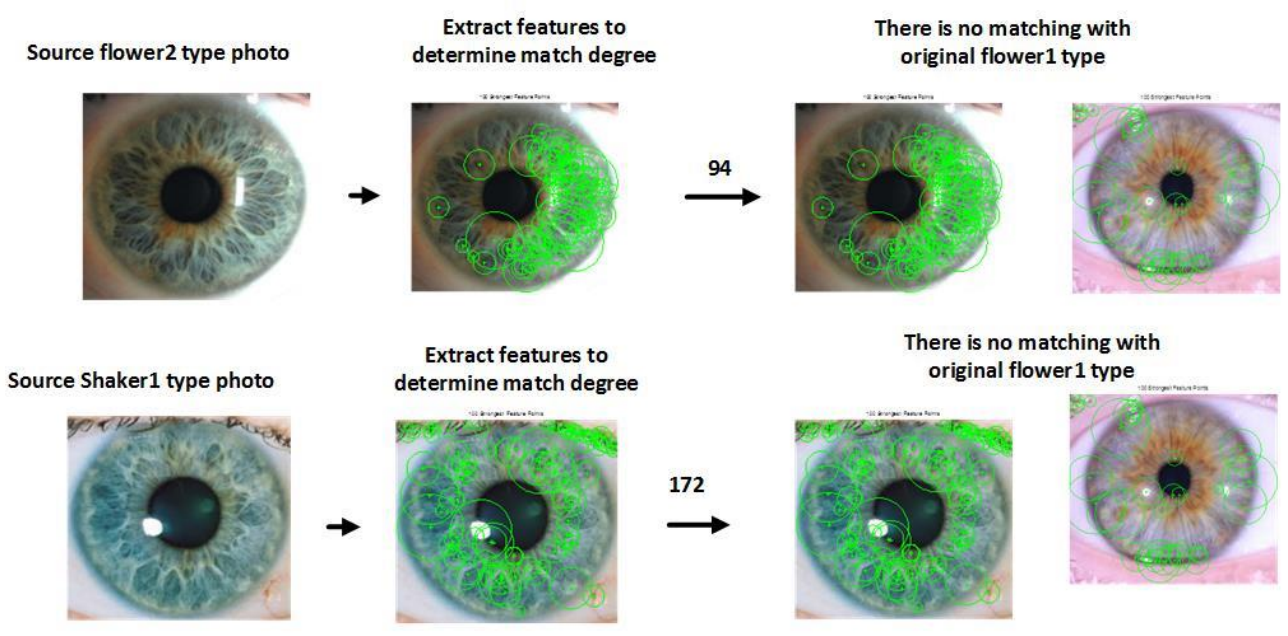

Source Shaker2 type photo
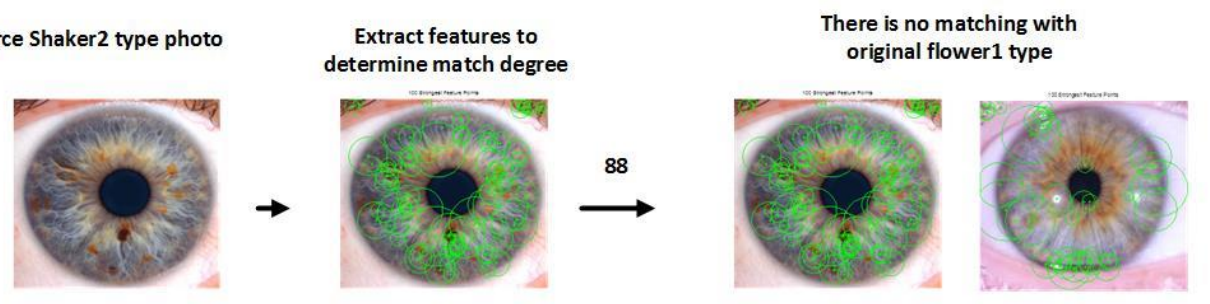

Figure 7. Study Matching of Samples with Stream Iris Type 


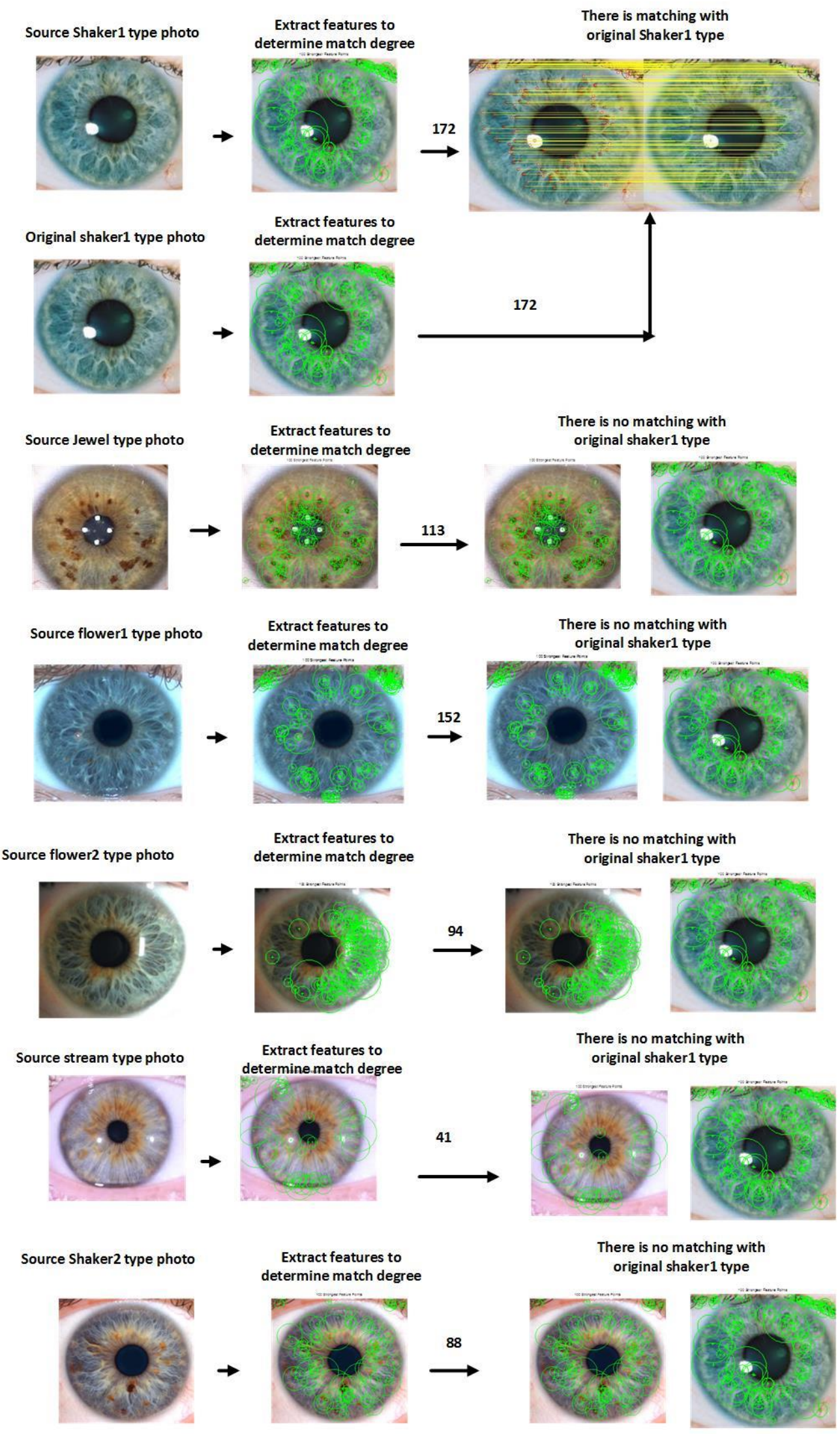

Figure 8. Study Matching of Samples with Shaker 1 Iris Type 
Table 1. Matching Degree of Samples with Jewel Iris Type

\begin{tabular}{|c|c|c|}
\hline Iris Type & Matching degree & Match or not? \\
\hline jewel & 113 & \multirow[t]{2}{*}{ Yes } \\
\hline jewel & 113 & \\
\hline Flower1 & 152 & \multirow[t]{2}{*}{ No } \\
\hline jewel & 113 & \\
\hline Flower2 & 94 & \multirow[t]{2}{*}{ No } \\
\hline jewel & 113 & \\
\hline Stream & 41 & \multirow[t]{2}{*}{ No } \\
\hline jewel & 113 & \\
\hline Shaker1 & 172 & \multirow[t]{2}{*}{ No } \\
\hline jewel & 113 & \\
\hline Shaker2 & 88 & \multirow[t]{2}{*}{ No } \\
\hline jewel & 113 & \\
\hline
\end{tabular}

Table 2. Matching Degree of Samples with Flower 1 Iris Type

\begin{tabular}{|c|c|c|}
\hline Iris Type & Matching degree & Match or not? \\
\hline Flower1 & 152 & \multirow[t]{2}{*}{ Yes } \\
\hline Flower1 & 152 & \\
\hline Jewel & 113 & \multirow[t]{2}{*}{ No } \\
\hline Flower1 & 152 & \\
\hline Flower2 & 94 & \multirow[t]{2}{*}{ No } \\
\hline Flower1 & 152 & \\
\hline Stream & 41 & \multirow[t]{2}{*}{ No } \\
\hline Flower1 & 152 & \\
\hline Shaker1 & 172 & \multirow[t]{2}{*}{ No } \\
\hline Flower1 & 152 & \\
\hline Shaker2 & 88 & \multirow[t]{2}{*}{ No } \\
\hline Flower1 & 152 & \\
\hline
\end{tabular}

Table 3. Matching Degree of Samples with Stream Iris Type

\begin{tabular}{|c|c|c|}
\hline Iris Type & Matching degree & Match or not? \\
\hline Stream & 41 & Yes \\
\hline Stream & 41 & \multirow{2}{*}{ No } \\
\hline Jewel & 113 & \\
\hline Stream & 41 & No \\
\hline Flower1 & 152 & \\
\hline Stream & 41 & \multirow{2}{*}{ No } \\
\hline & & \\
\hline Flower2 & 94 & \\
\hline Stream & 41 & \\
\hline & &
\end{tabular}




\begin{tabular}{|c|c|c|}
\hline Shaker1 & 172 & \multirow{2}{*}{ No } \\
\hline Stream & 41 & \\
\hline Shaker2 & 88 & No \\
\hline Stream & 41 & \\
\hline
\end{tabular}

\section{Table 4. Matching Degree of Samples with Shaker 1 Iris Type}

\begin{tabular}{|c|c|c|}
\hline Iris Type & Matching degree & Match or not? \\
\hline Shaker1 & 172 & \multirow[t]{2}{*}{ Yes } \\
\hline Shaker1 & 172 & \\
\hline Jewel & 113 & \multirow[t]{2}{*}{ No } \\
\hline Shaker1 & 172 & \\
\hline Flower1 & 152 & \multirow[t]{2}{*}{ No } \\
\hline Shaker1 & 172 & \\
\hline Flower2 & 94 & \multirow[t]{2}{*}{ No } \\
\hline Shaker1 & 172 & \\
\hline Stream & 41 & \multirow[t]{2}{*}{ No } \\
\hline Shaker1 & 172 & \\
\hline Shaker2 & 88 & \multirow[t]{2}{*}{ No } \\
\hline Shaker1 & 172 & \\
\hline
\end{tabular}

\section{Conclusion}

Iris recognition has explosion of interest in iris biometrics at recent years. This paper study SURF algorithm in matching of 4 iris types and the results show the method has fast, efficient and adequate with iris scanner devices.

\section{References}

[1] Biometrics:Overview.Biometrics.cse.msu.edu.https://web.archive.org/web/20120107071003/http://biom etrics.cse.msu.edu:80/info.html. (2007).

[2] A. Jain, L. Hong and S. Pankanti, "Biometric Identification", Communications of the ACM. vol. 43, No. 2, (2000).

[3] A. Jain, P. Flynn and A. Ross, "Handbook of Biometrics", Springer US. DOI 10. 1007/ 978 -0-38771041-9, (2008).

[4] A. Hake and P. Patil, "Iris Image Classification: A Survey", International Journal of Science and Research (IJSR), vol. 4, no. 1, (2015).

[5] G. Daugman, "High confidence visual recognition of persons by a test of statistical independence", IEEE Trans. Pattern Anal. Mach. Intell., vol. 25, no. 11, (1993), pp. 1148-1160.

[6] L. Masek, "Recognition of human iris patterns for biometric identification," B.S. dissertation, The School of Computer Science and Software Engineering, The University of Western Australia, Crawley WA, Perth, Australia, (2003).

[7] J. Huang, Y. Wang, T. Tan and J. Cui, "A new iris segmentation method for recognition", In Proc. 17th Int. Conf. Pattern Recogn.(ICPR), vol. 3, (2004), pp. 23-26.

[8] N. Singh, D. Gandhi and P. Singh, "Iris Recognition System Using a Canny edge detection and a circular Hough Transform", International Journal of Advances in Engineering \& Technology, (2011).

[9] R. Wildes, "Iris recognition: An emerging biometric technology", Proceedings of the IEEE, vol. 85, no. 9, (2014), pp. 1348-1363.

[10] V. Dorairaj, N. Schmid and G. Fahmy, "Performance evaluation of iris based recognition system implementing PCA and ICA encoding techniques. in Proc.", SPIE Conf. Biometric Technol. Human Identif.III, Orlando, FL, (2005).

[11] A. Ibrahim, "Iris Recognition using Haar Wavelet Transform", Journal of Al-Nahrain University, vol.17 no. 1, (2014), pp.180-186. 
[12] K. Miyazawa, K. Ito, T. Aoki, K. Kobayashi and H. Nakajima, "An efficient Iris Recognition using phase-based Image matching”, IEEE, (2005).

[13] K. Miyazawa, K. Ito, T. Aoki, K. Kobayashi and A. Katsumata, "An Iris recognition system using phase based image matching", IEEE, (2006),

[14] C. Durai and M. Karnan, "Iris Recognition Using Modified Hierarchical Phase-Based Matching", (HPM) Technique, (2010).

[15] G. Mabuza-Hocquet and F. Nelwamondo, "Fusion of Phase Congruency and Harris Algorithm for Extraction of Iris Corner Points", Third International Conference on Artificial Intelligence, Modelling and Simulation. IEEE computer society, (2015).

[16] F. Alonso-Fernandez, P. Tome-Gonzalez, V. Ruiz-Albacete and J. Ortega-Garcia, "Iris Recognition Based on SIFT Features", Biometrics, Identity and Security (BIdS). International Conference on. IEEE, (2009).

[17] S. Sangwan and R. Rani, "Hough Transform, SURF Technique For Automatic Iris Recognition", International Journal of Innovative Research in Science, Engineering and Technology (IJIRSET), vol. 4, no. $9,(\mathbf{2 0 1 5})$. 
International Journal of Signal Processing, Image Processing and Pattern Recognition Vol. 9, No. 12, (2016) 